\title{
Pengaruh Media, Temperatur dan Waktu Perlakuan Annealing Pada Spesimen Standar ASTM D638 Type IV Menggunakan Filamen ST PLA
}

\author{
Yulian Subakti*, Hasdiansah Zaldy Kurniawan \\ Teknik Mesin dan Manufaktur. Polman Babel. Kawasan Industri Air Kantung. Sungailiat \\ Bangka Belitung \\ *Subaktiyulian@gmail.com
}

\begin{abstract}
Fused Deposition Modeling (FDM) is a technique of 3D Printing machines that is popularly used to print products. The printed product certainly has the ideal tensile strength characteristics if it has a precise size and good shape according to the standard. One of the materials that can be processed in a 3D printing machine is ST PLA. Research in terms of tensile testing has been carried out on PLA/ABS materials. However, tensile testing with annealing process using ST PLA filament is still very rarely done. From these problems, it is necessary to research to obtain optimal process parameters on $3 \mathrm{D}$ printing machines, to obtain the highest tensile strength from the annealing process using ST PLA material. This research was conducted using a 3D printer DIY Prusa model with a printing area of XYZ, 300 $\mathrm{mm} \times 300 \mathrm{~mm} \times 350 \mathrm{~mm}$. The material used is ST PLA filament with a diameter of $1.75 \mathrm{~mm}$ in green. The process parameters in this research are layer thickness, nozzle temperature and flow rate. For annealing media use beach sand, coffee and wheat. The shape of the test specimen follows the ASTM D638 type IV standard. As for the design of the process parameters using the Taguchi $\mathrm{L}_{9}$ method $\left(3^{3}\right)$. The process parameter values that produce the highest tensile strength without annealing are layer thickness $0.3 \mathrm{~mm}$, nozzle temperature $205^{\circ} \mathrm{C}$, and flow rate $100 \%$. The annealing process parameters that produce the highest tensile strength are annealing time of 15 minutes, oven temperature of $110^{\circ} \mathrm{C}$, for annealing media using coffee.
\end{abstract}

Keywords : Annealing, ST PLA Filament, Taguchi Methode

\section{PENDAHULUAN}

Hadirnya teknologi 3D printing dalam dunia manufaktur membawa perubahan besar pada dunia industri. Teknologi yang juga dikenal dengan sebutan additive manufacturing sebenarnya sudah hadir sejak tahun 1980-an. Proses pembuatan objek dilakukan dengan cara menambahkan ribuan lapisan kecil yang dikombinasikan untuk hasilkan barang jadi atau finished products. Salah satu metode yang sangat populer dalam additive manufactur adalah fused depasition modelling (Knic.co.id).

Fused depasition modelling (FDM) merupakan salah satu metode yang cukup populer dalam additive manufactur dimana produk yang dihasilkan melalui proses ini berpotensi untuk dapat bersaing dengan metode manufaktur konvensional (injection moulding). Bahan/material yang digunakan dalam teknologi $3 \mathrm{~d}$ printing adalah plastik.

Plastik mengalami perkembangan dan penggunaan yang sangat luas. Ditambah dengan hadirnya teknologi 3D printing. salah satu polymer plastik dalam teknologi 3D printing adalah filamen ST PLA.

ST PLA merupakan pengembangan filamen PLA yang dikomposkan dengan aditif spesial, tidak berpengaruh biodegradasi, beberapa kali lebih keras dibandingkan dengan 
PLA normal sehingga bisa menghasilkan kekuatan yang lebih baik, ikatan yang luar biasa dan tahan akan benturan (www.primes3d.com). Dalam rangka peningkatan properti filament ST PLA perlu dimodifikasi untuk memperbaiki sifatnya, salah satunya dengan proses annealing, pada proses annealing diperlukan beberapa variasi antara lain media, waktu annealing dan temperatur annealing. Variasi faktor tersebut tidak memiliki nilai pasti dalam pengerjaanya, sehingga dibutuhkan pencarian nilai yang tepat untuk mendapatkan produk yang sesuai dengan harapan.

(Slavkovic, Grujovic, Disic, \& Radovanovic, 2017) telah melakukan penelitian yang berjudul "Pengaruh Arah Pengumuman dan Pencetakan Pada Sifat Mekanis Polimer Memori Bentuk PLA Yang Dihasilkan Oleh Pemodelan Deposisi Fuse”. Dari penelitian ini didapatkan hasil kekuatan akhir rata-rata adalah $33,83 \mathrm{MPa}( \pm 0,46 \mathrm{MPa})$ untuk sampel yang dicetak dan 44,06 $\mathrm{MPa}( \pm 0,6 \mathrm{MPa})$ untuk sampel yang dianil. Spesimen yang dianil menunjukkan peningkatan kekuatan ultimit sebesar 30,25\% dibandingkan dengan sampel yang dicetak. Anil menyebabkan peningkatan 19\% dalam modulus elastisitas rata-rata, dari $1,35 \mathrm{GPa}( \pm 0,057)$ untuk sampel yang dicetak menjadi $1,67 \mathrm{GPa}( \pm 0,122)$ untuk sampel yang dianil, tegangan-regangan untuk sampel yang dicetak dan dianil menyebabkan peningkatan $9 \%$ dalam modulus elastisitas ratarata dari $1,65 \mathrm{GPa}( \pm 0,12)$ untuk sampel yang dicetak hingga $1,82 \mathrm{GPa}( \pm 0,097)$ untuk sampel yang dianil. (1)

(Srithep, Nealey, \& Sheng Trung, 2012 ) juga melakukan penelitian tentang “ Effects of Annealing Time and Temperature on the Crystallinity and Heat Resistence Behavior of Injection-Molded Poly(lactic acid) “. Dari penelitian ini didapatkan hasil Hasil penelitian, Kekuatan tarik dari campuran PLA anil terasa lebih tinggi dibandingkan dengan spesimen yang dicetak, Pada suhu anil $80{ }^{\circ} \mathrm{C}$ kekuatan tarik untuk spesimen PLA yang dicetak dan 3 spesimen PLA yang di annealing, dengan waktu Anil 14, 23 dan 30 menit ditemukan sekitar 65,3 71,7 73,5 dan 76,0 Mpa. Masing-masing yang mencapai peningkatan maksimum 17\% modulus tarik, spesimen PLA yang di anil penuh meningkat maksimum $6,4 \%$. Jenis yang sama tren ditemukan untuk spesimern yang di anil pada suhu $65{ }^{\circ} \mathrm{C}$. Untuk waktu yang lebih lama, Kekuatan tarik dan modulus spesimen PLA yang di Anil penuh pada suhu Anil $65{ }^{0} \mathrm{C}$ ditemukan meningkat sekitar $26 \%$ dan $13 \%$. (2).

Oleh karena itu, pada penelitian ini menggunakan filamen ST PLA yang akan dilakukan proses pencarian nilai terhadap pengaruh dari media pasir pantai, kopi, gandum beserta temperatur annealing $(100,110,120)$ dan waktu annealing $(15,20$, 25). Untuk mengetahui faktor mana yang paling ideal untuk meningkatkan kualitas dari filamen ST PLA. 


\section{METODE PENELITIAN}

Tahapan penelitian yang dilakukan mengikuti diagram aliran yang ditunjukkan pada gambar 1.
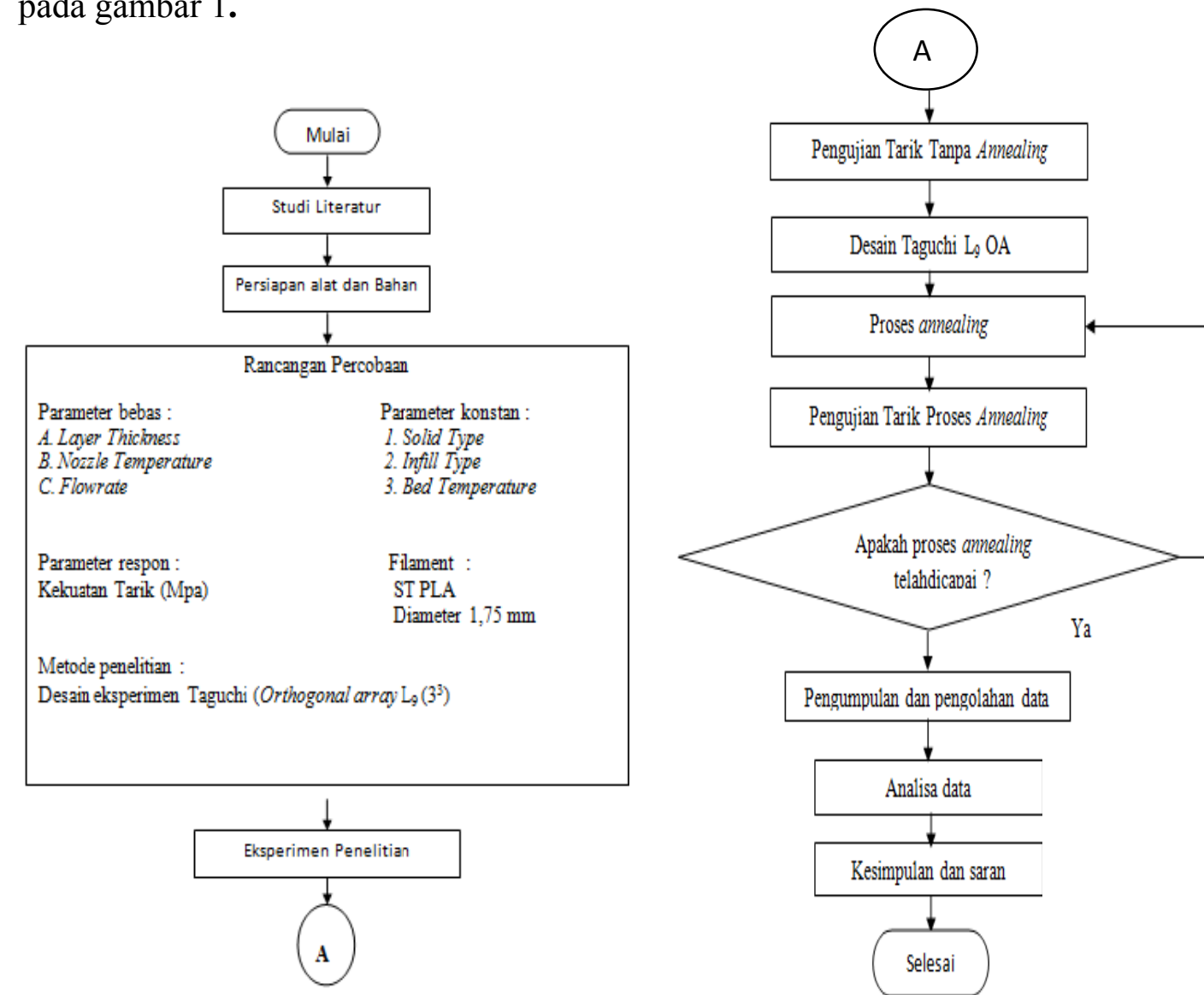

Gambar 1. Diagram penelitian

\subsection{Objek Penelitian}

Objek penelitian dilakukan pada mesin 3D printing area XYZ dengan dimensi 300 $\mathrm{mm}$ x $300 \mathrm{~mm}$ x $350 \mathrm{~mm}$ dengan menggunakan nozzle berukuran 0,4 mm. Material yang digunakan filamen ST PLA dengan diameter 1,75 $\mathrm{mm}$. Desain objek didesaian menggunakan software gambar dengan bentuk dan dimensi bedasarkan ASTM D638 type IV. Ditunjukkan pada gambar 2.

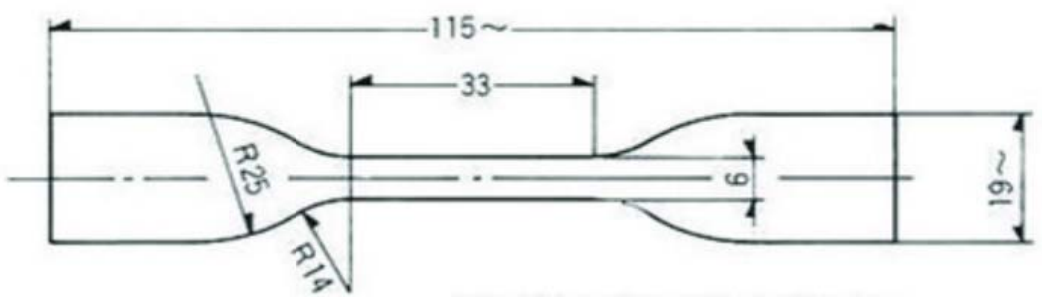

Gambar 2. Dimensi dan bentuk spesimen uji

\subsection{Alat dan Bahan}

1. Mesin 3D Printing Anet 8 pro dengan volume XYZ $300 \mathrm{~mm}$ x $300 \mathrm{~mm}$ x $350 \mathrm{~mm}$. Dengan menggunakan nozzle berukuran $0,4 \mathrm{~mm}$. Bahan yang digunakaan pada penelitian ini adalah filamen ST PLA, warna hijau seperti gambar berikut. 

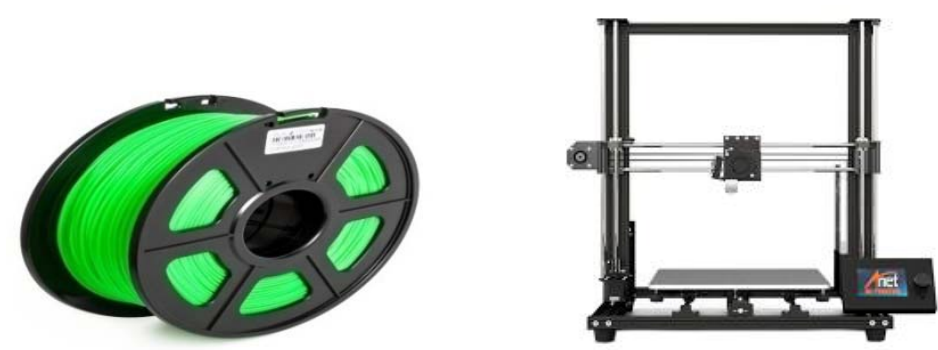

Gambar 3. Filamen ST PLA dan mesin 3D printing

Tabel 1. Spesifikasi Filamen ST PLA

\begin{tabular}{ll}
\hline Filament Diameter & $1.75 \mathrm{~mm}$ \\
\hline Recommend Extruder Temperature & $190-220{ }^{0} \mathrm{C}$ \\
\hline Recommend Platform Temperature & $45-60{ }^{\circ} \mathrm{C}$ \\
\hline Density & $1,24 \mathrm{~g} / \mathrm{cm}^{3}$ \\
\hline Tensile strenght & $47,9 \mathrm{Mpa}$ \\
\hline Elongation at Break & $82 \%$ \\
\hline
\end{tabular}

2. Mesin uji tarik merk Zwick Roell dan Oven merk SAKAI seperti gambar berikut

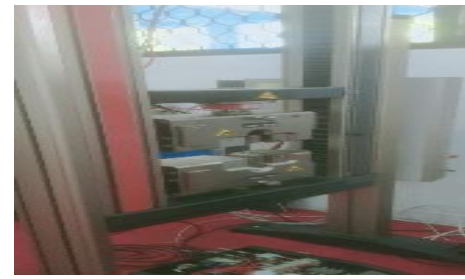

Gambar 4. Mesin uji tarik

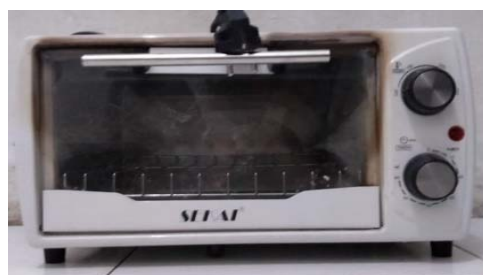

Gambar 5. Oven untuk proses annealing

3. Spesimen Uji seperti pada gambar 6 .

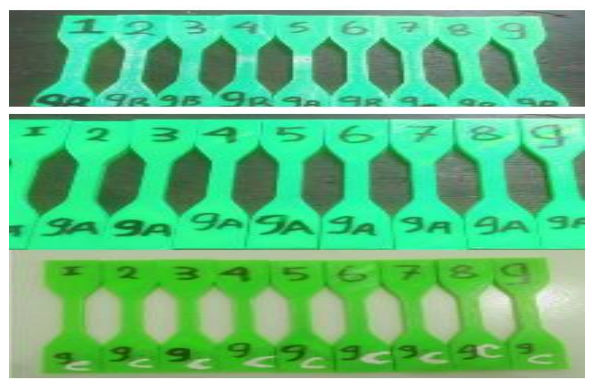

Gambar 6. Spesimen uji

\subsection{Langkah-langkah penelitian}

Tahapan pada penelitian ini berurutan dimulai dengan persiapan mesin 3D printing, filamen ST PLA, software ideamaker 3.6.1 dan software gambar. Semua alat dan bahan yang berhubungan dengan penelitian ini akan disiapkan dengan sebaik mungkin supaya proses penelitian ini terarah. Setelah persiapan penelitian selesai, maka akan dilanjutkan dengan penentuan parameter proses cetak seperti layer thickness, nozzle temperature dan flowrate seperti pada tabel 2. 
Tabel 2. Parameter Cetak Desain Taguchi $\mathrm{L}_{9}\left(\mathrm{O}^{\mathrm{A}}\right)$

\begin{tabular}{cccc}
\hline $\begin{array}{c}\text { Exp. } \\
\text { No }\end{array}$ & $\begin{array}{c}\text { Layer Thickness } \\
(\mathbf{m m})\end{array}$ & $\begin{array}{c}\text { Nozzle Temperature } \\
(\mathbf{0} \mathbf{C})\end{array}$ & $\begin{array}{c}\text { Flowrate } \\
(\mathbf{\%})\end{array}$ \\
\hline 1 & 0,1 & 195 & 95 \\
2 & 0,1 & 200 & 100 \\
3 & 0,1 & 205 & 105 \\
4 & 0,2 & 195 & 100 \\
5 & 0,2 & 200 & 105 \\
6 & 0,2 & 205 & 95 \\
7 & 0,3 & 195 & 105 \\
8 & 0,3 & 200 & 95 \\
9 & 0,3 & 205 & 100 \\
\hline
\end{tabular}

Dari tabel 2 nilai kekuatan tarik tertinggi terdapat pada spesimen nomor 9 (sembilan) dengan layer thickness $(0,3 \mathrm{~mm})$ nozzle temperature $\left(205{ }^{0} \mathrm{C}\right)$ dan flowrate (100\%) menghasilkan kekuatan tarik sebesar 47,66 Mpa. Selanjutnya spesimen yang mengahasilkan kekuatan tarik tertinggi akan dicetak kembali menggunakan mesin 3D printing seperti pada gambar 7 untuk proses annealing. Dengan pengaturan proses annealing seperti tabel 3.

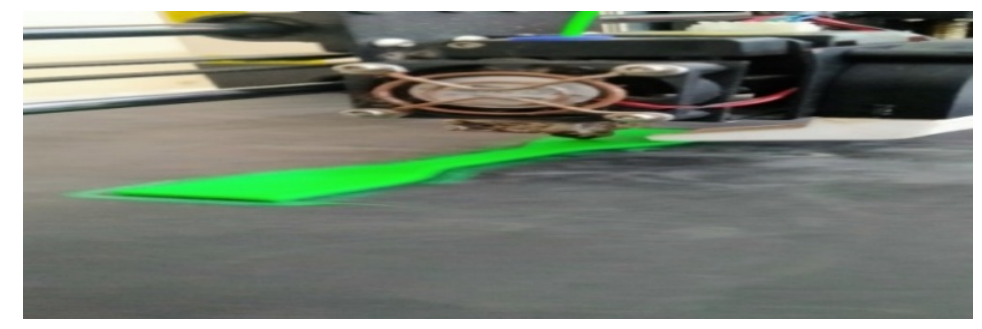

Gambar 7. Proses pembentukan spesimen uji

Tabel 3. Faktor variasi Annealing Taguchi $\mathrm{L}_{9} \mathrm{OA}$

\begin{tabular}{cccl}
\hline Exp. No & Waktu Annealing & Temperatur Annealing & Media Annealing \\
\hline 1 & 15 & 100 & Pasir pantai \\
2 & 15 & 110 & Kopi \\
3 & 15 & 120 & Gandum \\
4 & 20 & 100 & Kopi \\
5 & 20 & 110 & Gandum \\
6 & 20 & 120 & Pasir pantai \\
7 & 25 & 100 & Gandum \\
8 & 25 & 110 & Pasir pantai \\
9 & 25 & 120 & Kopi \\
\hline
\end{tabular}

\section{HASIL DAN PEMBAHASAN}

Pengambilan data penelitian dilakukan dengan cara mengkombinasikan parameter proses. Adapun parameter proses pada penelitian ini yang mempengaruhi kekuatan tarik dari filamen ST PLA seperti layer thickness, temperature nozzle dan flow rate. Hasil pengujian dapat dilihat pada tabel 4. 
Tabel 4. Rata-rata hasil pengujian tarik dari proses annealing

\begin{tabular}{ccclcccccc}
\hline Exp & $\begin{array}{c}\text { Waktu } \\
(\mathbf{m i n})\end{array}$ & $\begin{array}{c}\text { Suhu } \\
\left(\mathbf{(}^{\mathbf{C}} \mathbf{)}\right.\end{array}$ & Media & Rep.1 & Rep 2 & Rep.3 & Rep.4 & Jumlah & $\begin{array}{c}\text { Rata-rata } \\
\text { (Mpa) }\end{array}$ \\
\hline 1 & 15 & 100 & Pasir pantai & 44,9 & 41,5 & 47,1 & 48,0 & 181,5 & 45,37 \\
2 & 15 & 110 & Kopi & 48,1 & 51,5 & 47,8 & 51,2 & 198,6 & 49,65 \\
3 & 15 & 120 & Gandum & 50,2 & 46,8 & 50,1 & 47,8 & 198,6 & 48,72 \\
4 & 20 & 100 & Kopi & 43,9 & 44,5 & 46,8 & 51,5 & 186,7 & 46,67 \\
5 & 20 & 110 & Gandum & 42,8 & 42,9 & 43,4 & 49,5 & 178,6 & 44,65 \\
6 & 20 & 120 & Pasir pantai & 46,1 & 46,5 & 44,6 & 46,9 & 184,1 & 46,02 \\
7 & 25 & 100 & Gandum & 45,3 & 44,4 & 53,6 & 51,8 & 195,1 & 48,77 \\
8 & 25 & 110 & Pasir pantai & 42,9 & 45,2 & 52,7 & 52,4 & 193,2 & 48,3 \\
9 & 25 & 120 & Kopi & 47,9 & 51,2 & 42,9 & 50,2 & 192,2 & 48,05 \\
\hline
\end{tabular}

\subsection{Perhitungan Respon Signal to Noise}

Dari data yang telah diperoleh dapat dilakukan pencarian nilai rasio $\mathrm{S} / \mathrm{N}$ pada tiap parameter dengan large the better dan berikut diperoleh hasil perhitungan respon dapat dilihat pada gambar 8 berikut dan tabel 5 .

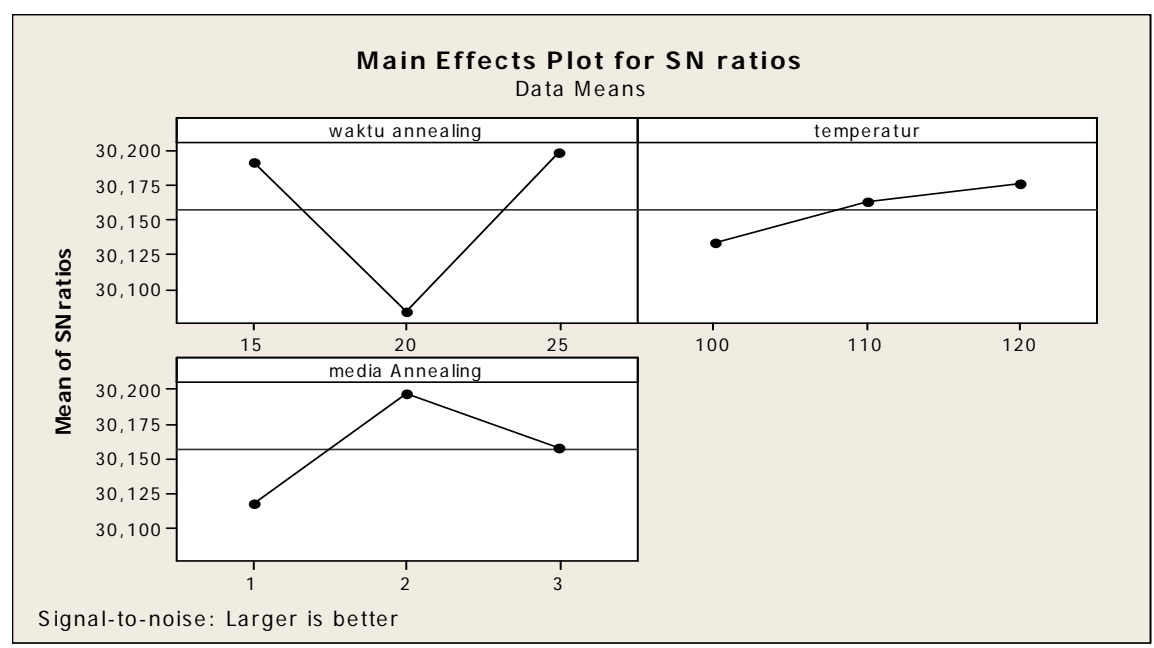

Gambar 8. Plot rasio $\mathrm{S} / \mathrm{N}$ untuk respon kekuatan tarik

Tabel 5. Respon rasio $\mathrm{S} / \mathrm{N}$

\begin{tabular}{cccc}
\hline Level & Waktu Annealing (min) & Temperature $\left({ }^{\mathbf{0}} \mathbf{C}\right)$ & Media Annealing \\
\hline 1 & 30,19 & 30,13 & 30,12 \\
2 & 30,08 & 30,16 & 30.20 \\
3 & 30,20 & 30,18 & 30,16 \\
Delta & 0,12 & 0,04 & 0,08 \\
rank & 1 & 3 & 2 \\
\hline
\end{tabular}

Dari gambar 9 dan tabel 4 dapat diketahui parameter proses mana yang mempengaruhi dari kekuatan tarik filamen ST PLA yaitu waktu annealing 15 (min), media annealing (kopi) dan waktu annealing $120{ }^{\circ} \mathrm{C}$. 


\subsection{Hasil Analisisi Variansi (ANAVA)}

Tabel 6. Hasil Analisi Variansi (ANAVA)

\begin{tabular}{ccccccc}
\hline Sumber & DF & Seq SS & Adj SS & Adj MS & F & P \\
\hline Waktu Annealing & 2 & 0,3428 & 0,3428 & 0,1714 & 1,21 & 0,453 \\
Temperature & 2 & 0,0388 & 0,0388 & 0,0194 & 0,14 & 0,880 \\
Media Annealing & 2 & 1,1320 & 0,1320 & 0,0660 & 0,46 & 0,683 \\
Error & 2 & 0,2842 & 0,2842 & 0,1421 & & \\
Total & 8 & 0,7978 & & & & \\
\hline
\end{tabular}

Hipotesis Pengujian :

$\mathrm{H}_{0}$ : Tidak ada pengaruh

$\mathrm{H}_{1}$ : Ada pengaruh

Kriteria pengujian : Tolak $\mathrm{H}_{0}$ jika $\mathrm{F}$ hitung $>\mathrm{F}$ tabel $(\alpha=5 \%)$

Hasil dari analisis pada tabel 6 dapat dilihat pada tabel 7 berikut

Tabel 7. Keputusan Uji

\begin{tabular}{cccc}
\hline $\begin{array}{c}\text { Komparasi Terhadap } \\
\text { Respon }\end{array}$ & F-Test & $\begin{array}{c}\text { F-Tabel } \\
\mathbf{( 0 , 0 5 ; 2 ; 8 )}\end{array}$ & Keputusan Uji \\
\hline Waktu annealing & 1,21 & & H0 Diterima \\
Temperature & 0,14 & 4,46 & H0 Diterima \\
Media annealing & 0,46 & & H0 Diterima \\
\hline
\end{tabular}

Dari tabel 6 dapat memberikan informasi bahwa dari 3 variasi parameter proses annealing tidak ada pengaruh yang signifikan terhadap kekuatan tarik dari filamen ST PLA.

\section{KESIMPULAN}

Hasil pengujian tarik dari proses annealing dapat ditarik kesimpulan bahwa kekuatan tarik tertinggi dari filamen ST PLA dari proses annealing dengan 3 variasi parameter proses yaitu, waktu annealing, temperatur dan media annealing. Nilai kekuatan tarik tertinggi terdapat pada spesimen nomor 2 (dua) dengan waktu annealing (15 menit), temperatur annealing $\left(110^{\circ} \mathrm{C}\right)$ dan media annealing (kopi). Menghasilkan kekuatan tarik sebesar 49,65 MPa. Sedangkan parameter yang menghasilkan kekuatan tarik terendah terdapat pada spesimen nomor 5 (lima) dengan waktu annealing (20 menit), temperatur annealing $\left(110{ }^{\circ} \mathrm{C}\right)$, untuk media annealing menggunakan gandum, yang menghasilkan kekuatan tarik sebesar 44,65 MPa.

\section{DAFTAR PUSTAKA}

[1]. A Akbar, Nurdin and Hermawan, Yuni. (2014), Pengaruh Variasi Holding Time dan Temperatrur Paduan Polipropilena (PP) dengan Serat Sabut Kelapa Terhadap Kekuatan Tarik dan Bending, Pada Proses Injection Molding. Jurnal ROTOR, pp. 1-4.

[2]. Andriyansyah, Deni, Herianto and Purfaji. (2018), Optimasi Parameter Proses 3D Printing Terhadap Kekuatan Tarik Filamen Polylactic Acid Menggunakan Metode Taguchi. 2018, Seminar Naisonal Pendidikan Teknik Otomotif, pp. 6168. 
[3]. Butt, Javaid and Bhaskar, Raghunath. (2020), Investigating the Effects of Annealing on the Mechanical Properties of FFF-Printed Thermoplastics, Manufacturing and Materials Processing, pp. 2-20.

[4]. Geng, Peng, et al. (2018), Effects of Thermal Processing and Heat Treatment Condition on 3D Printing PPS Properties.Polymers, pp. 2-12.

[5]. Halawa, Erniwati. (2013), Pengarug Annealing Terhadap Sifat Fisis Dan Mekanik Polietelen -Grafting -Maleat Anhidride (PE-g-MAH). Eienstein, pp. 8-14.

[6. Kholil, A., Aufi, F. and Syaefudin, E.A. 2020, Pengaruh Layer Thickness Dan Orientasi 3D Printing Terhadap Uji Tarik Material ABS . NCIET , pp. 219-226.

[7]. Slavkovic, Vukasin, et al. (2017), Pengaruh Arah Pengumuman dan Pencetakan Pada Sifat Mekanis Polimer Memori Bentuk PLA yang Dihasilkan oleh Pemodelan Deposisi Fused., Serbian society of mechanics mountain tara, pp. 1-8.

[8]. Srithep, Yotta, Nealey, Paul and Sheng Trung, Lih. (2012), Effects of Annealing Time and Temperature on The Crystallinity and Heat Resistance Behavoir Of injection-Molded Poly(lactic-Acid) . Polymer Engineering and Science, pp. 1-9.

[9]. Suzen, Z.S., Hasdiansah and Yulianto. (2020), Pengaruh Tipe Infill dan Temperatur Nozzle Terhadap Kekuatan Tarik Produk 3D Printing Filamen PLA+ Esun. Jurnal Teknologi Manufaktur, pp. 74-80.

[10]. yu, long, et al. (2008), Effect of Annealing and Orientation on Microstructures and mechanical Properties of Polylactic Acid. POLYMER ENGINEERING AND SCIENCE, pp. 635-641. 